\title{
Effect of Temperature and Nanoparticle Concentration on the Viscosity of Glycerine-water based $\mathrm{SiO}_{2}$ Nanofluids
}

\author{
M. L.R. Chaitanya Lahari , P. Haseena Bee, P.H.V. Sesha Talpa Sai , K.S. Narayanaswamy, S. \\ Devaraj, K.V. Sharma
}

\begin{abstract}
Dynamic viscosity of $\mathrm{SiO}_{2} / 22 \mathrm{~nm}$ nanofluids prepared in a glycerine-water (30:70 by volume) mixture base liquid, referred to as GW70, is measured experimentally. Nanofluids with concentrations of $0.2,0.6$, and 1.0 percent are produced, and viscosity measurements are carried out at temperatures ranging from 20 to $80^{\circ} \mathrm{C}$ using a LVDV-2T model Brookfield Viscometer. The particle size and elemental composition of nanoparticles are determined using FESEM and EDX. XRD images confirm the $\mathrm{SiO}_{2}$ peaks in the crystalline structure. The rheology of nanofluids is influenced by the nanoparticle's concentration. In the experimental temperature and concentration range, nanofluids show Newtonian behavior. The viscosity of nanofluids enhanced as particle concentration increased and reduced as temperature increased. For 1.0 percent vol. concentration at $20^{\circ} \mathrm{C}$, the maximum viscosity value is achieved, and for 0.2 percent vol. concentration at $80^{\circ} \mathrm{C}$, the lowest viscosity value is observed. The viscosity of the glycerine-water base fluid was also determined at 20, 40, 60, and 80 degrees Celsius. The viscosity ratio of nanofluids to the base liquid is found to be more than one for all the nanofluids. This viscosity data is useful to estimate HTC of glycerine-water-based silica nanofluids.
\end{abstract}

Keywords: Nanofluids, Glycerine-Water Base Liquid, Sion, Viscosity, FESEM.

\section{INTRODUCTION}

$\mathbf{N}_{\text {anofluids are used for improved heat transmission and }}$ cooling processes in many industries. They are also being used in energy harvesting and thermal management systems such as microelectromechanical systems, electronic cooling systems, microfluidics, pharmacy, automobile and medical, etc. [1-3] As a consequence, this relatively new type of fluids is emerging as a hotly debated topic among researchers all around the world.

Manuscript received on October 04, 2021.

Revised Manuscript received on October 18, 2021.

Manuscript published on November 30, 2021.

*Correspondence Author

M.L.R. Chaitanya Lahari*, Research Scholar, School of Mechanical Engineering, Reva University, Bangalore, India.

P. Haseena Bee, Research Scholar, School of Mechanical Engineering, Reva University, Bangalore, India.

P.H.V. Sesha Talpa Sai, Professor \& Director-R\&D, Department of Mechanical Engineering, Malla Reddy College of Engineering and Technology, Hyderabad, India.

K.S. Narayanaswamy, Professor \& Director, School of Mechanical Engineering, Reva University, Bangalore, India.

S. Devaraj, Professor, School of Mechanical Engineering, Reva University, Bangalore, India.

K.V. Sharma, Emeritus Professor, Centre for Energy Studies, Jawaharlal Nehru Technological University, Hyderabad, India.

(c) The Authors. Published by Blue Eyes Intelligence Engineering and Sciences Publication (BEIESP). This is an open access article under the CC BY-NC-ND license (http://creativecommons.org/licenses/by-nc-nd/4.0/)
The majority of previous studies explored the higher thermal properties, especially TC of these NF's and emphasized their possible applications in many areas. Studies on the viscosity variations of these nanofluids with nanoparticle size, shape, type, concentration, temperature are comparatively less. [4-9] Viscosity, on the other hand, is an essential characteristic of fluids, particularly in terms of its practical uses in fluid movement and heat transmission. The viscosity of the heat transfer fluid greatly influences the pumping power and HTC. Thermal conductivity accounts for the majority of published papers on nanofluids (56\%) followed by viscosity (24\%), and other thermal and physical characteristics account for the remainder. In recent years, however, there has been a modest rise in the research on the VST of NF's. Nanofluids have a substantially greater viscosity than their base fluids, which rise with increasing NP concentration. The VST findings of nanofluids cannot be predicted using current classical models. All newly suggested empirical correlations, on the other hand, are based on fitting experimental findings and are neither generally recognized nor applicable to other kinds of nanofluids. [10-13] Furthermore, many literature searches on the viscosity of nanofluids showed significant dispersion and inconsistency. The viscosity findings from various research groups, even for the identical nanofluids, varied significantly, as described in the published reviews. The use of various nanoparticle sizes and purity, type of equipment used to measure or geometries, the shear rate examined, the magnitude of clustering, and different methods of preparation may all contribute to the inconsistency and scattered results. Furthermore, the impact of NP concentration on the VST of nanofluids has received the greatest attention among the research. The effect of additional factors such as rise in temperature, type of base liquids, preparation methods, and particle size, type, and shape on the VST of NF's must be investigated to fully use nanofluids' enhanced thermal characteristics in different applications. [14-18] Most nanofluids surpass conventional HT fluids used as base fluids in terms of heat transmission, despite their high viscosity. Prasher et al. [19] utilized thermal and hydraulic research and showed that if the increase in VST of nanofluids is 4 times higher than the relative rise in TC of NF over the base liquid, then the NF can be useful in heat transfer enhancement.

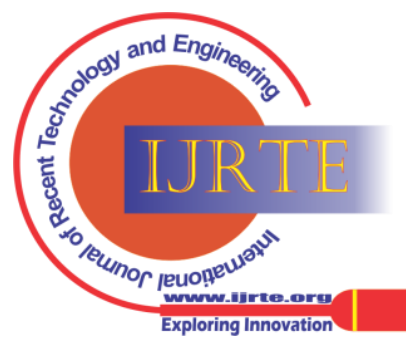


This implies that if a nanofluid's TC increases by $25 \%$ at a particular ' $\varphi$ ' value of nanoparticles, the rise in VST of that nanofluid at that same ' $\varphi$ ' must be within $100 \%$ of the base fluids to surpass it in heat transfer. Although the mixing of NP's increases the viscous nature of the base liquid, the enhanced thermal and physical properties of the NF's will compensate for this shortcoming. This makes the use of nanofluids an emerging candidate for cooling and HT applications.

\section{VISCOSITY STUDIES OF NANOFLUIDS}

Masuda et al. [20] determined the VST of water-based $\mathrm{Al}_{2} \mathrm{O}_{3} / 13 \mathrm{~nm} ; \quad \mathrm{SiO}_{2} / 12 \mathrm{~nm} \mathrm{NF}$ for a range of volume concentration of 1.30 to $4.30 \%$ and $1.10-2.40 \%$ respectively in the temperature range of $31-86^{\circ} \mathrm{C}$. A viscosity enhancement of 300 and 200 percent for $\mathrm{Al}_{2} \mathrm{O}_{3}$ and $\mathrm{SiO}_{2}$ respectively were reported. Pak and Cho [21] experimented with $\mathrm{Al}_{2} \mathrm{O}_{3}$ with $13 \mathrm{~nm}$ and $\mathrm{TiO}_{2}$ with $27 \mathrm{~nm}$ nanofluids in water for volume concentrations of $0.99-10 \%$ and reported viscosity enhancement of 150 and 200 percent at $25^{\circ} \mathrm{C}$. Heris et al. [22] used water- $\mathrm{Al}_{2} \mathrm{O}_{3} / 20 \mathrm{~nm}$; $\mathrm{CuO} / 29 \mathrm{~nm}$ nanofluids for particle loading of $0.2-3.0 \%$ and observed maximum viscosity enhancement of 40 and 60 percent respectively at $24^{\circ} \mathrm{C}$. Azmi et al. [23] used $\mathrm{SiO}_{2} / 50 \mathrm{~nm}$ in water up to 4.0 volume concentrations and observed viscosity enhancement of $49 \%$ at $30^{\circ} \mathrm{C}$. Namburu et al. $[24,25]$ experimented with $0.6-12 \%$ concentrations of $\mathrm{CuO} / 29 \mathrm{~nm}$ in water and obtained a maximum viscosity enhancement of $350 \%$ at $35^{\circ} \mathrm{C}$. They also dispersed $\mathrm{SiO}_{2}$ particles of 29, 50, and $100 \mathrm{~nm}$ size in EG-water in the wt. ratio 60:40 to measure viscosity and specific heat in temperature ranging from $-30-50^{\circ} \mathrm{C}$. The viscosity of $\mathrm{SiO}_{2}$ nanofluids enhanced with concentration at about 1.8 times compared to the base liquid and decreased exponentially with temperature. For the same volumetric concentration of $8 \%$ viscosity increment was more for lower particle diameter. With a $10 \%$ concentration of $\mathrm{SiO}_{2}$ the specific heat was $12 \%$ lower than base liquid. Akilu et al. [26] contrasted the viscosity of non-porous EG and glycerol-based silica $/ 15-22 \mathrm{~nm}$ nanoparticles, in the concentrations of $0.5-2.0 \%$ and measured properties for a range over $30-80^{\circ} \mathrm{C}$. A reduction in viscosity of $95 \%$ and $80 \%$ for $\mathrm{SiO}_{2}$ nanofluid was observed in base liquids Glycerol and EG respectively. The viscosity of the nanofluid must be determined before accurate pumping power, Prandtl and Re numbers, and the HTC can be calculated. Only a few researches have looked at the rheological characteristics of silicon dioxide nanoparticle suspensions, and there is no data on the VST of $\mathrm{SiO}_{2}$ NF's in a glycerine-water base liquid that the author is aware of. As a result, these measurements are critical for the effective use of NF's in different applications. Silicon dioxide nanoparticles are the cheapest nanoparticles, with a minimal study on their rheological characteristics, making them an intriguing test subject. The nanofluids were prepared and the viscosity was determined using silicon dioxide nanoparticles (22nm) in various concentrations. These NP's were mixed in a base liquid of glycerine and water (30:70 by volume) and then tested for rheological properties at temperatures ranging from 20 to 80 degrees Celsius.

\section{EXPERIMENTATION}

\section{A. Preparation of nanofluids}

$\mathrm{SiO}_{2}$ nanofluids of $0.2,0.6$ and $1.0 \%$ concentration are prepared using a two-step dispersion synthesis technique. A 70:30 mixture of glycerine-water in 30:70 ratio by volume referred to as GW70, is used as a base liquid. $\mathrm{SiO}_{2}$ nanoparticles with an average size of 22nm are procured from Sigma Aldrich. Homogenous solutions of three separate nanofluids with the above $\varphi$ values are produced by magnetic stirring for two hours and then ultrasonicated for one hour. Ultrasonication is a commonly used method for mixing extremely entangled or aggregated nanoparticles at a frequency of $40 \mathrm{kHz}$ with a power output of $100 \mathrm{~W}$. The produced $\mathrm{SiO}_{2}$ nanofluids are shown in Figure 1 at $\varphi=0.2$, 0.6 , and $1.0 \%$.

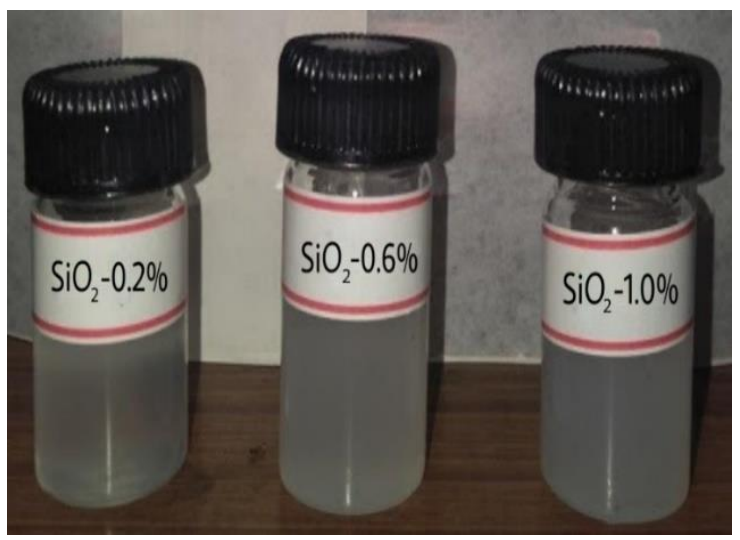

Fig. 1 SiO2 Nanofluids of 0.2, 0.6 and 1.0\% Concentration in glycerol-water (30:70) Base Liquid

\section{B. Measurement of Viscosity:}

The viscosity of NF's at various ' $\varphi$ ' values and in different base fluids is an essential factor to consider when choosing dispersion conditions. The viscosity of NF's was evaluated at different shear rates using a Brookfield LVDV-2T touch screen model viscometer shown in Figure 2. This programmable device may be used for data gathering as well as control. When the instrument is begun to measure viscosity, the auto-zero setting allows the initial zero measurements to be set. The viscosity test and torque, spindle rotation speed, and temperature may all be set according to the user's needs. A calibrated spring immerses the suitable spindle supplied with the instrument in the test solution. To raise the measurement temperatures in $5^{\circ} \mathrm{C}$ increments, a constant temperature bath is utilized. As a reference fluid, the device is calibrated by conducting experiments initially using deionized water. The spindle rotates inside the fluid and generates torque. Viscosity is computed using this torque and other input parameters. In this experiment, a constant temperature bath is utilized to raise the temperature to between 10 and $100^{\circ} \mathrm{C}$. More descriptions about the working principle and specifications of LVDV-2T Brookfield Viscometer are reported by Lahari et al. [27].

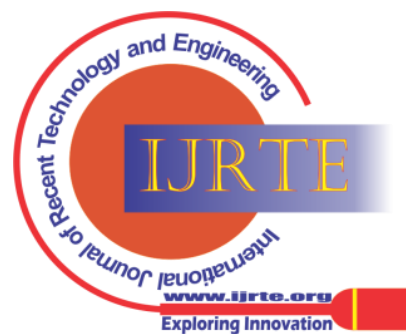



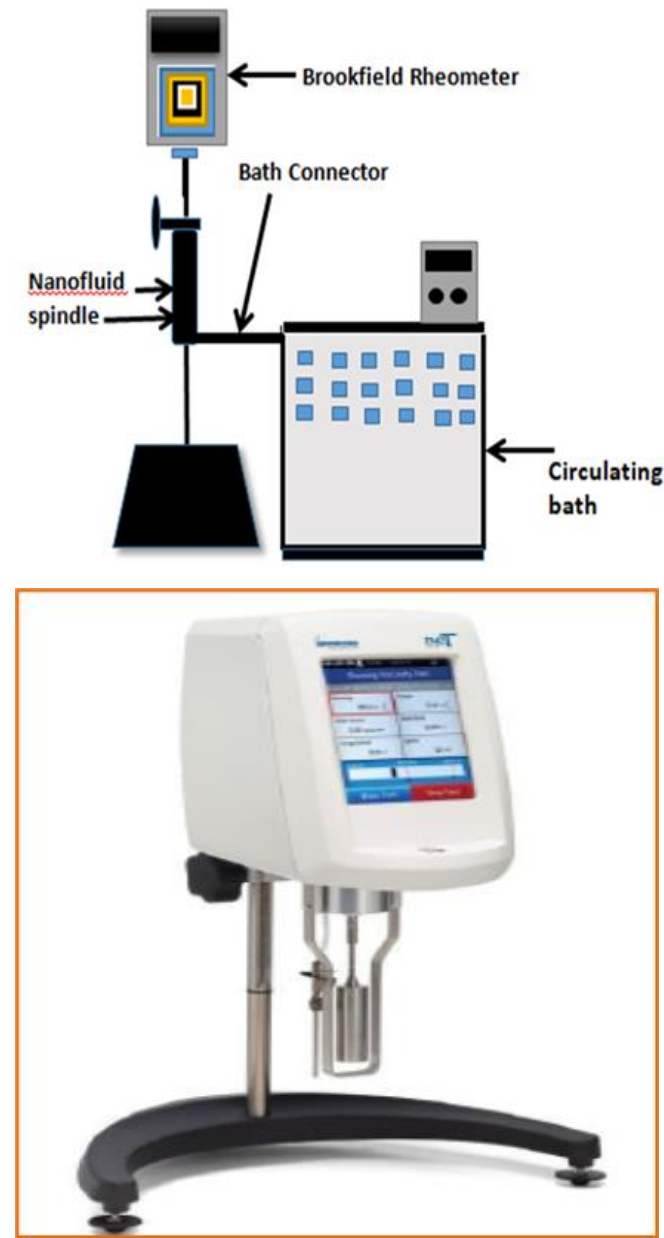

Fig. 2: Experimental setup of LVDV-2T Brookfield Viscometer

\section{RESULTS AND DISCUSSION}

\section{A. Characterization of $\mathrm{SiO}_{2}$ Nanoparticles:}

FESEM micrographs of $\mathrm{SiO}_{2}$ nanoparticles are shown in Figure 3. $\mathrm{SiO}_{2}$ nanoparticles have an average particle size (APS) of 22nm. The FESEM picture shows a uniform and monodispersed particle distribution. EDX spectroscopy of silica nanoparticles is shown in Figure 4. This spectrum measures the elemental composition of $\mathrm{SiO}_{2}$ nanoparticles. As illustrated in Figure 4, silica and oxygen have elemental weight percentages of 38.72 and 61.28 , respectively, and atomic percentages of 26.47 and 73.53 . The oxygen and silica binding energies are shown by the peaks at 0.5 and $1.8 \mathrm{keV}$, respectively.

XRD peaks with corresponding crystalline values of $\mathrm{SiO}_{2}$ NP's are shown in Figure 5. XRD analysis of $\mathrm{SiO}_{2}$ nanoparticles is carried out using a powder $\mathrm{X}$-ray diffractometer with a diffraction angle (2 thetas) between 0 and 80 degrees. Broadenings of the peaks due to the nanocrystalline size of the particles can be observed. Three peaks belonging to the planes of silica appear at (101), (200), and (220) peaks. Both EDX and XRD pattern shows no impurities other than the presence of Silica and Oxygen elements.

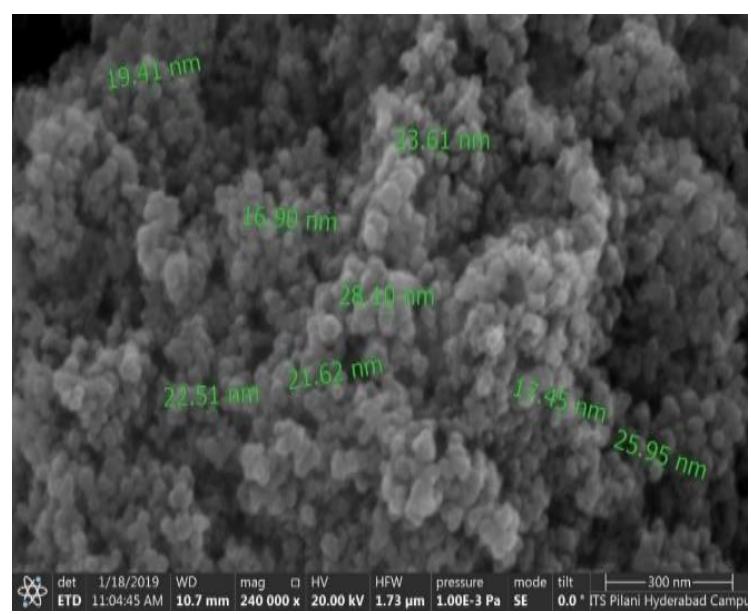

Fig. 3 FESEM Micrographs of SiO2 Nanoparticles (APS-22nm)

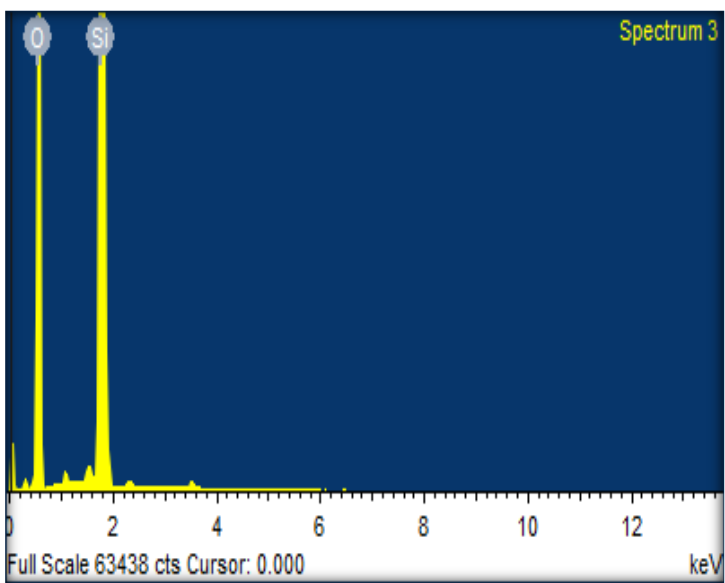

\begin{tabular}{|c|c|c|}
\hline Element & Weight \% & Atomic \% \\
\hline $\mathrm{O}$ & 61.28 & 73.53 \\
\hline $\mathrm{Si}$ & 38.72 & 26.47 \\
\hline
\end{tabular}

Fig. 4 EDX Spectroscopy of SiO2 Nanoparticles with Elemental Composition

\section{B. Viscosity of Base Liquid and SiO2 Nanofluids:}

Dynamic viscosity variation of base liquid with concentration and temperature is illustrated in Figure 6. The data is compared with the values estimated with the theoretical model developed by Cheng [28] valid for aqueous mixtures. The viscosity of GW mixture for $\varphi=0-100 \%$; $\mathrm{T}=$ $0-100^{\circ} \mathrm{C}$ in power form can be estimated with Eqs. (1) - (6).

$$
\begin{gathered}
\mathrm{a}=0.705-0.0017 \mathrm{~T} \\
\mathrm{~b}=(4.9+0.036 \mathrm{~T}) \mathrm{a}^{2.5} \\
\alpha=1-C_{m}+\frac{a b C_{m}\left(1-C_{m}\right)}{a C_{m}+b\left(1-C_{m}\right)} \\
\mu_{w}=1.790 \exp \left(\frac{(-1230-T) T}{36100+360 T}\right)
\end{gathered}
$$

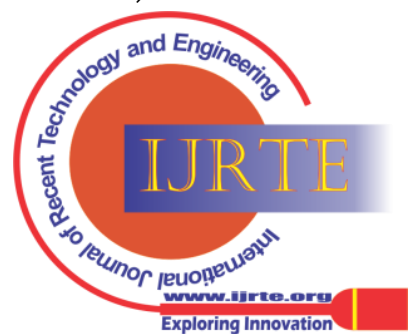




$$
\begin{gathered}
\mu_{g}=12100 \exp \left(\frac{(-1233+T) T}{9900+70 T}\right) \\
\mu_{g w}=\mu_{w}^{\alpha} \mu_{g}^{1-\alpha}
\end{gathered}
$$

Where $a, b$ are coefficients; $g$ and $w$ represent glycerol and water, $\alpha$ is the weighing factor in the range of 0 to 1 ; $C_{m}$ is glycerol concentration in mass. The viscosity of glycerol $\mu_{g}$ is obtained in centipoise (or $0.001 \mathrm{Ns} / \mathrm{m}^{2}$ ) and $T$ is in ${ }^{\circ} \mathrm{C}$. Empirical data deviated to a maximum of $14 \%$ with the computed values using Eqs. (1) - (6).

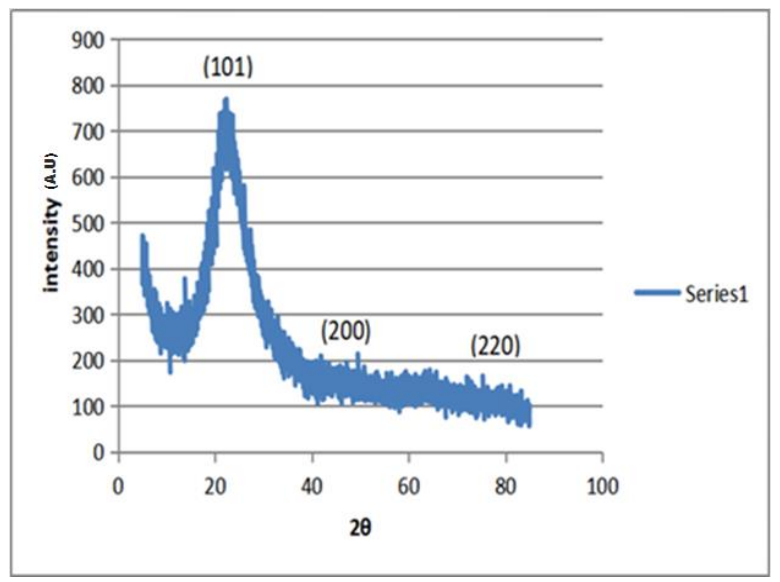

Fig.5 XRD Image of SiO2 nanoparticles

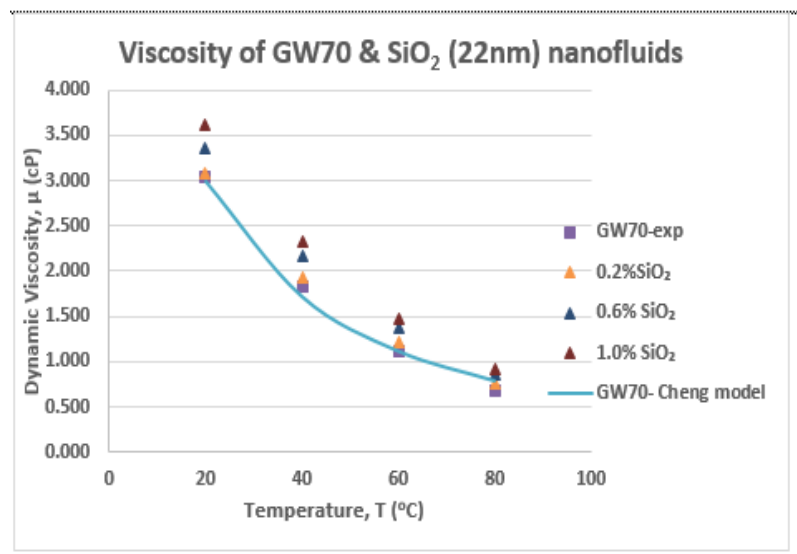

Fig. 6 Viscosity of GW70 and SiO2 nanofluids

Figure 6 also illustrates the dynamic viscosity variation of $\mathrm{SiO}_{2}$ NF's along with GW70 base liquid against ' $T$ ' and ' $\varphi$ '. The viscosity of nanofluids is seen to rise with ' $\varphi$ ' and decrease with ' $\mathrm{T}$ ' in the studied range of $20-80^{\circ} \mathrm{C}$. At elevated temperatures, intermolecular distance from each other increases causing decreased viscosity. At $20^{\circ} \mathrm{C}$ and $0.2 \%$ concentration, the enhancement in viscosity is $1.46 \%$. The enhancement in VST of $\mathrm{SiO}_{2} \mathrm{NF}^{\prime}$ 's at $\varphi=1.0 \%$ and at $20^{\circ} \mathrm{C}$ is $18.93 \%$ higher than the GW70.

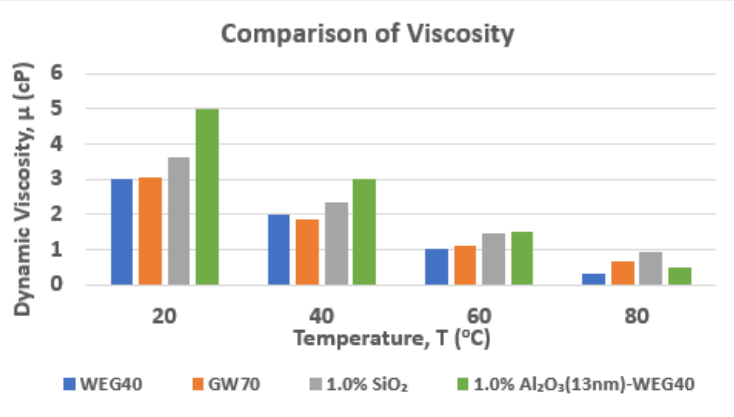

Fig. 7 Comparison of Viscosity of GW70 and $\mathrm{SiO}_{2}$
nanofluids

Jensen et al. [29] observed that "water acts as a lubricant, softening the hydrogen bonding which contributed to the macroscopic viscosity of the glycerol-water mixture". Takamura et al. [30] observed that "the increase in viscosity of glycerol-water mixtures with the addition of glycerol is highly non-linear" and the variation in the aqueous phase was over three orders of magnitude. Viscosity is reported to be independent of the material and increase with concentration, decrease raise in ' $T$ ' and ' $\varphi$ '. Machrafi [31] reported that the density of the nanoparticles, nanofluid, base fluid influences the nanofluid VST. The average particle size of $\mathrm{SiO}_{2}$ considered in this work is $22 \mathrm{~nm}$ and the density of $\mathrm{SiO}_{2}$ nanoparticles is $2220 \mathrm{~kg} / \mathrm{m}^{3}$. Viscosity data of $\mathrm{SiO}_{2}$ nanofluids in GW70 base liquid is not available in published works for comparison. Azmi et al. [32] determined the viscosity of water-EG in $60: 40$ as a base liquid at $20^{\circ} \mathrm{C}$ to be $3.0 \mathrm{cp}$ which is similar to GW70 viscosity at $20^{\circ} \mathrm{C}$. Therefore, the viscosity of $\mathrm{Al}_{2} \mathrm{O}_{3} / 13 \mathrm{~nm}$ nanofluid is taken for comparison which is shown in Figure 7. The viscosity of $\mathrm{Al}_{2} \mathrm{O}_{3}(13 \mathrm{~nm})$ nanofluids is greater at $20^{\circ} \mathrm{C}$ and $40^{\circ} \mathrm{C}$ which might be due to the smaller size of the particle. Figure 8 depicts the viscosity ratio of NF's to base liquid in terms of temperature and ' $\varphi$ '. The viscosity ratio is the ratio of the nanofluids' viscosity to that of the base liquid. The fact that the ratio is greater than one indicates that the mixing of NP's increases the viscosity of the liquid over the base liquid. For all concentrations, the VST enhanced with the addition of NP's and declined with the increase in temperature. Azmi et al. [23] observed a similar pattern in his work.

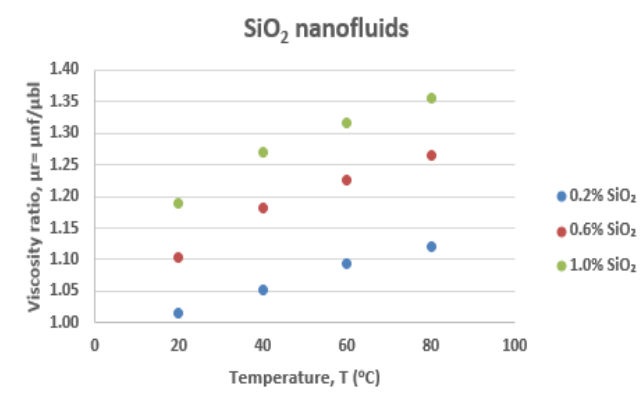

Fig.8: Variation of Viscosity Ratio with Temperature and Concentration 


\section{CONCLUSION}

$\mathrm{SiO}_{2}$ nanoparticles of $\varphi=0.2,0.6$, and $1.0 \%$ vol. concentrations are dispersed in a 70:30 ratio of the water-glycerine base fluid. The viscosity of the prepared nanofluids was measured in the range of $20-80^{\circ} \mathrm{C}$ using Brookfield Viscometer. The VST of nanofluids increased as ' $\varphi$ ' of nanoparticles increase and reduced as the temperature increase.

\section{ACKNOWLEDGMENT}

The authors gratefully acknowledge the support extended by the School of Mechanical Engineering, REVA University, Bangalore, India and the Department of Mechanical Engineering, Malla Reddy College of Engineering and Technology, Hyderabad, India.

\section{NOMENCLATURE}

\begin{tabular}{|l|l|}
\hline APS & Average Particle Size \\
\hline BF & Base Fluid \\
\hline BL & Base Liquid \\
\hline EDX & Energy Dispersive X-Ray \\
\hline EG & Ethelyn Glycol \\
\hline FESEM & Field Emission Scanning Electron Microscope \\
\hline HTC & Heat Transfer Coefficient \\
\hline HT & Heat Transfer \\
\hline NF & Nano Fluid \\
\hline NP & Nano Particle \\
\hline T & Temperature \\
\hline TC & Thermal Conductivity \\
\hline VST & Viscosity \\
\hline$\varphi$ & Particle Concentration \\
\hline
\end{tabular}

\section{REFERENCES}

1. Choi SUS, Zhang ZG, Keblinski P. Nanofluids. In: Nalwa HS, editor. Encyclopedia of nanoscience and nanotechnology. Los Angeles: American Scientific Publishers; 2004. p. 757-73. technology. New Jersey: Wiley; 2008.

3. Yu W, France DM, Routbort JL, Choi SUS. Review and comparison of nanofluid thermal conductivity and heat transfer enhancements. Heat Transf Eng 2008; 29:432-60.

4. Thomas S, Sobhan CBP. A review of experimental investigations on thermal phenomena in nanofluids. Nano Res Lett 2011; 6:377. nanofluids: a state-of-the-art review. Microfluid Nanofluid 2010; 8:145-70.

6. Murshed SMS, Leong KC, Yang C. Investigations of thermal conductivity and viscosity of nanofluids. Int J Therm Sci 2008; 47:560-8.

7. Kleinstreuer C, Feng Y. Experimental and theoretical studies of nanofluid thermal conductivity enhancement: a review. Nanoscale Res Lett 2011; 6:229.

8. Murshed SMS, Nieto, de Castro CA. Superior thermal features of carbon nanotubes based nanofluids - a review. Renew Sustain Energy Rev 2014; 37:155-67.

9. HŞ Aybar, Sharifpur M, Azizian MR, Mehrabi M, Meyer JP. A review of thermal conductivity models for nanofluids. Heat Transf Eng 2015; 36:1085-110.

10. Vajjha RS, Das DK. A review and analysis on influence of temperature and concentration of nanofluids on thermophysical properties, heat transfer and pumping power. Int J Heat Mass Transf 2012;55: 4063-78.

11. Sundar LS, Sharma KV, Naik MT, Singh MK. Empirical and theoretical correlations on viscosity of nanofluids: a review. Renew Sustain Energy Rev 2013; 25:670-86.

12. Murshed SMS, Santos FJV, Nieto de Castro CA. Viscosity of metal oxide based nanofluids. In: Murshed SMS, Nieto de Castro CA, editors. Nanofluids: synthesis, properties and applications. New York: 2014, Nova Science Publishers.

13. Meyer JP, Adio SA, Sharifpur M, Nwosu PN. The viscosity of nanofluids: a review of the theoretical, empirical, and numerical models. Heat Transf Eng 2016; 37:387-421.
2. Das SK, Choi SUS, Yu W, Pradeep T. Nanofluids: science and

5. Özerinç S, Kakaç S, Yazıcıoğlu AG. Enhanced thermal conductivity of

14. Chen H, Ding Y, Tan C. Rheological behaviour of nanofluids. New J Phys 2007; 9:367.

15. Mahbubul IM, Saidur R, Amalina MA. Latest developments on the viscosity of nanofluids. Int J Heat Mass Transf 2012; 55:874-85.

16. Mishra PC, Mukherjee S, Nayak SK, Panda A. A brief review on viscosity of nanofluids. Int Nano Lett 2014; 4:109-20.

17. Nwosu PN, Meyer JP, Sharifpur M. A review on parametric investigation into nanofluid viscosity models. J Heat Transf 2014; 5:031008.

18. Sharma AK, Tiwari AK, Dixit AR. Rheological behavior of nanofluids: a review. Renew Sustain Energy Rev 2016; 53:779-91.

19. Prasher R, Song D, Wang J, Phelan P. Measurements of nanofluid viscosity and its implications for thermal applications. Appl Phys Lett 2006; 89:133108.

20. H. Masuda, A. Ebata, K. Teramae, and N. Hishinuma, Alternation of thermal conductivity and viscosity of liquid by dispersing ultra-fine particles (dispersion of c $\Upsilon-\mathrm{Al}_{2} \mathrm{O}_{3}, \mathrm{SiO}_{2}$ and $\mathrm{TiO}_{2}$ ultra-fine particles), NetsuBussei 4, 1993, 227-233.

21. Pak, B. C., and Cho, Y. I., Hydrodynamic and Heat Transfer Study of Dispersed Fluids with Submicron Metallic Oxide Particles, Exp. Heat Transfer, 11, 1998, 151-170.

22. S.Z. Heris, S.G. Etemad, M. Nasr Esfahany, Experimental investigation of oxide nanofluids laminar flow convective heat transfer, Int. Commun. Heat MassTransfer 33, 2006, 529-535.

23. Azmi, W., K. V. Sharma, P. K. Sarma, R. Mamat, S. Anuar, and V. D. Rao., Experimental determination of turbulent forced convection heat transfer and friction factor with $\mathrm{SiO}_{2}$ nanofluid, Experimental Thermal and Fluid Science 51,2013, 103-111.

24. P.K. Namburu, D.P. Kulkarni, D. Misra, D.K. Das, Viscosity of copper oxide nanoparticles dispersed in ethylene glycol and water mixture, Exp. Therm. Fluid Sci. 32,2007, 397-402.

25. P. Namburu, D. Kulkarni, A. Dandekar, D. Das, Experimental investigation of viscosity and specific heat of silicon dioxide nanofluids, Micro Nano Lett., IET 2,2007, 67-71.

26. Suleiman Akilua, Aklilu Tesfamichael Baheta, Alina Adriana Minea, K.V. Sharma, Rheology and thermal conductivity of non-porous silica $\left(\mathrm{SiO}_{2}\right)$ in viscous glycerol and ethylene glycol-based nanofluids, International Communications in Heat and Mass Transfer 88,2017, 245-253.

27. M.L.R. Chaitanya Lahari, P.H.V. Sesha Talpa Sai, K.S. Narayanaswamy, P. Haseena Bee, S. Devaraj, K.V. Sharma; Experimental determination of viscosity of Water-Glycerine based $\mathrm{Cu}$ nano-fluids, Materials Today: Proceedings 19 (2019) 517-520.

28. Nian-Sheng Cheng, Formula for the Viscosity of a Glycerol-Water Mixture, Ind. Eng. Chem. Res. 2008, 47, 3285-3288.

29. M. H. Jensen, C. Gainaru, C. Alba-Simionesco, T. Hecksher K. Niss, Slow rheological mode in glycerol and glycerol-water mixtures, Phys. Chem. Chem. Phys., 2018,20, 1716-1723.

30. Koichi Takamura, HerbertFischer , NormanR.Morrow , Physical properties of aqueous glycerol solutions, Journal ofPetroleumScienceandEngineering98-99, 2012, 50-60.

31. Hatim Machrafi, Universal relation between the density and the viscosity of dispersions of nanoparticles and stabilized emulsions, Nanoscale, 2020,12, 15081-15101.

32. W.H. Azmi, N.A. Usri, Rizalman Mamat, K.V. Sharma, M.M. Noor, Force convection heat transfer of $\mathrm{Al}_{2} \mathrm{O}_{3}$ nanofluids for different based ratio of water: Ethylene glycol mixture, Applied Thermal Engineering 112, 2017, 707-719.

\section{AUTHORS PROFILE}

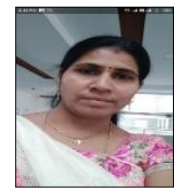

Ms. M L R Chaitanya Lahari , is presently working as Associate Professor, Malla Reddy College of Engineering and Technology (Autonomous) and Research Scholar of School of Mechanical Engineering, REVA University, Bangalore. She obtained her B. Tech and $\mathrm{M}$. Tech degrees from JNTU with distinction. She has 6 years of Teaching and Research experience apart from 2 years of industry exposure. She has 10 International and National Publications/Conference proceedings, three Patents, 3 books/book chapters to her credit, and guided many PG and UG students' projects. Her research interests are Nanofluids in Energy and Heat Transfer applications, Solar Energy Conversion and Storage Devises, Design and Management of Thermal Systems, Heat Transfer, Non-Conventional Energy Sources. 


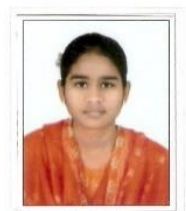

Ms. P Haseena Bee, is presently working as Associate Professor, Malla Reddy College of Engineering and Technology (Autonomous) and Research Scholar of School of Mechanical Engineering, REVA University, Bangalore. She obtained her B. Tech and $\mathrm{M}$. Tech degrees from JNTU-Hyderabad with distinction. She has 05 International and National Publications/Conference proceedings, 2 Patents, 2 Books/Book Chapters to her credit and guided many PG and UG students' projects. Her research interests are Nanofluids in Manufacturing applications, Solar Energy Conversion and Storage Devises.

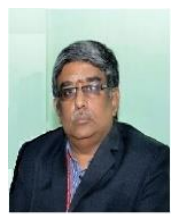

Dr. P H V Sesha Talpa Sai, is presently working as Professor and Director, Malla Reddy College of Engineering and Technology (Autonomous). He obtained his Doctoral degree from JNTU, Hyderabad. He is having 16 years of industry and 16 years of academic and research experience. He is visiting faculty at Lincoln University College (LUC), Malaysia. He is guiding five Ph.D. Scholars from different Universities. He has 52 International and National Publications/Conference proceedings, 10 patents published, and 6 books/book chapters to his credit. His research interests are Nano Composite Materials for Solar Energy Conversion and Storage, Biofuels and Lubricants, Nanofluids in Energy and Heat Transfer applications, etc.

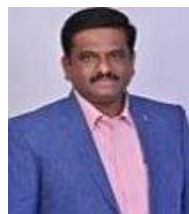

Dr. K S Narayanaswamy, is presently working as Professor \& Director, School of Mechanical Engineering, Reva University, Bangalore. He obtained his doctoral degree from Bangalore University and is having 17 years of teaching and research experience. He is guiding four Ph.D. Scholars from different Universities. He has more than 20 International and National Publications/Conference proceedings, 3 patents published, and 1 book/book chapter to his credit and guided many PG and UG students' projects. He won the best teacher award in the year 2015 .

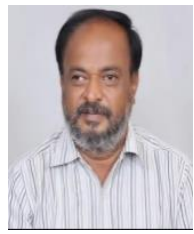

Dr. Devaraj S, is presently working as a Professor at, School of Mechanical Engineering, Reva University, Bangalore. He obtained his doctoral degree from IIT, Madras, and is having 28 years of teaching and research experience. He is guiding four Ph.D. Scholars from different Universities. He has more than 15 International and National Publications/Conference proceedings.

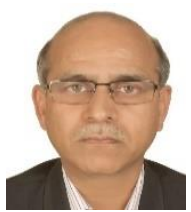

Dr. Viswanatha Sharma Korada, Emeritus Professor, Center for Energy Studies, JNTUH is having 40 years of experience in academics and research. He also served in reputed institutions such as University Malaysia Pahang (UMP) from 2009 to 2012 and University Technology Petronas (UTP) from 2014 to 2016. He has published numerous peer-reviewed articles in journals dealing with Thermal fluid problems, Heat Transfer using Nanofluids, Energy Systems etc. and guided 20 doctoral students. His research interests are Nanofluid Heat Transfer, Turbulent Convection, Solar Thermal Energy Conversion, Electronic Cooling, Packed Bed Thermal Energy Storage, Boiling Heat Transfer.

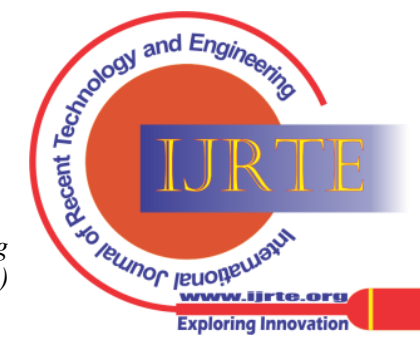

